\title{
Maximum Power Point Tracker Controller Using Fuzzy Logic Control with Battery Load for Photovoltaics Systems
}

\author{
Mazen Yeselam Baramadeh, Mohamed Abd Almonem Abouelela, Saad Mubarak Alghuwainem \\ Electrical Engineering Department, King Saud University, Riyadh, Saudi Arabia \\ Email: mazen.b1775@hotmail.com, mabouelela@ksu.edu.sa, saadalgh@ksu.edu.sa
}

How to cite this paper: Baramadeh, M.Y., Abouelela, M.A.A. and Alghuwainem, S.M. (2021) Maximum Power Point Tracker Controller Using Fuzzy Logic Control with Battery Load for Photovoltaics Systems. Smart Grid and Renewable Energy, 12, 163-181. https://doi.org/10.4236/sgre.2021.1210010

Received: September 21, 2021

Accepted: October 26, 2021

Published: October 29, 2021

Copyright (c) 2021 by author(s) and Scientific Research Publishing Inc. This work is licensed under the Creative Commons Attribution International License (CC BY 4.0). http://creativecommons.org/licenses/by/4.0/

\begin{abstract}
The target of this paper is to model a Maximum Power Point Tracker (MPPT) using a Fuzzy Logic Control (FLC) algorithm and to investigate its behavior with a battery load. The advantage of this study over other studies in this field is that it considers a battery load rather than the commonly used resistive load especially when we deal with the relationship between MPPT and system load. The system is about $60 \mathrm{~kW}$ which is simulated under various environmental conditions by Matlab/Simulink program. For this type of non-linear application, FLC naturally offers a superior controller for the real load case. The artificial intelligence approach also benefits from this method for overcoming the complexity of nonlinear system modelling. The results show that FLC provides high performance for MPPT of PV system with battery load due to its low settling time and limited oscillation around the steady state value. These are assistant factors for increasing battery life.
\end{abstract}

\section{Keywords}

MPPT Controller, Fuzzy Logic Control, PV System, Matlab Simulink

\section{Introduction}

PV systems need special control techniques to ensure the taking out of the utmost available power, otherwise, the system may not be sustainable. As there be learn the PV generator which also known as PV array, generate DC power. The output energy of PV modules had greatly influenced by environmental conditions or factors. Effects on external performance are characterized by photovoltaic modules from ambient environmental influences such as irradiation, the temperature of module and outer humidity. The standard test condition (STC) is 
essential because environmental conditions have a significant impact on $\mathrm{PV}$ module output energy which are Solar incident: $1000 \mathrm{~W} / \mathrm{m}^{2}$, temperature module: 25 Co and distribution of the solar spectrum: AM1.5G. However, the real outdoor conditions seldom satisfy STC. As a result, solar radiation growth is relative to the power supply of $\mathrm{PV}$, which is a negative linear link among output power and temperature variations [1] [2].

In spite of attractive features of the PV cells, their energy efficiency is still very low. The PV cell has non-linear current-voltage and power-voltage properties (i.e. $\mathrm{I}-\mathrm{V}$ and $\mathrm{P}-\mathrm{V}$, respectively) which vary greatly with the ambient environmental conditions (i.e. irradiation and temperature) that be mentioned before. Figure 1 and Figure 2 illustrate the effect. On the other hand, only under uniform solar radiation, the PV cell shows a single point of operation, called the point of maximum power (MPP), (see Figure 3), Where the maximum voltage and current occur (i.e. $V_{M}$ and $I_{M}$, consecutively). This makes extracting the maximum power from the photovoltaic cell a rather difficult task under inconsistent atmospheric conditions [3].
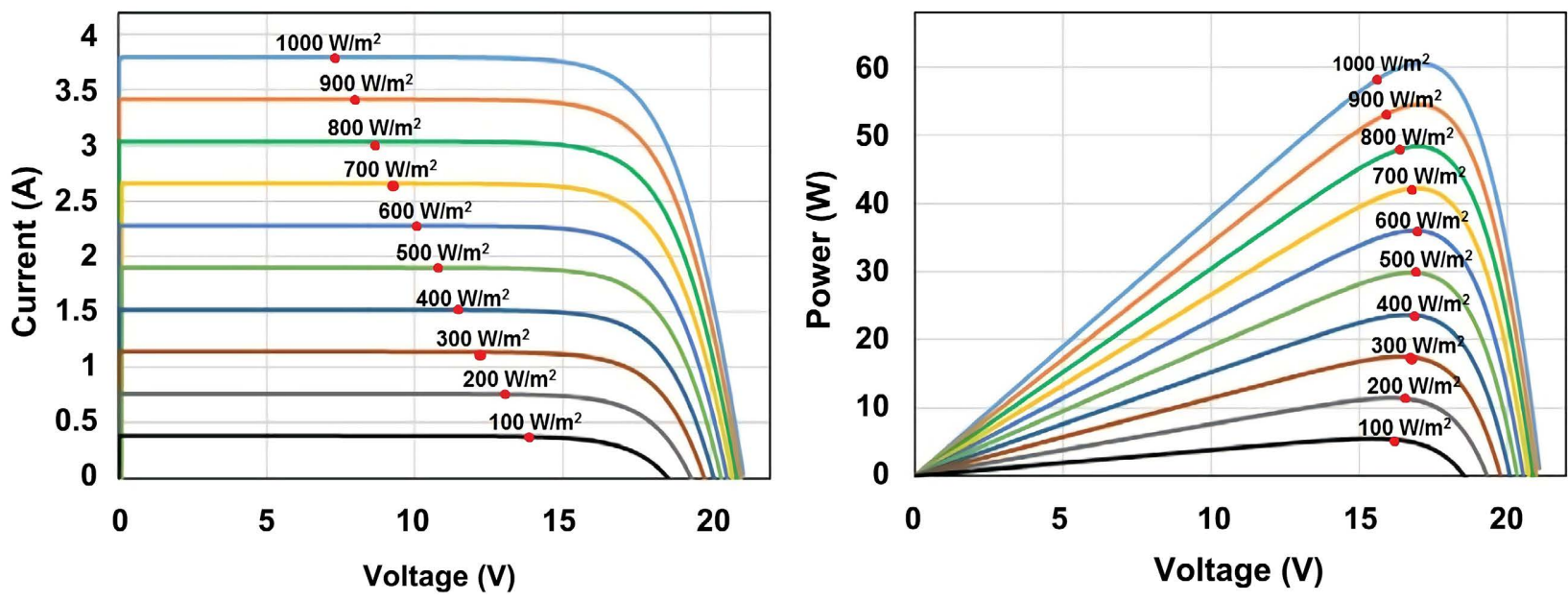

Figure 1. I-V and P-V characteristics for various values of solar irradiation at $\mathrm{T}=25^{\circ} \mathrm{C}$ [4].
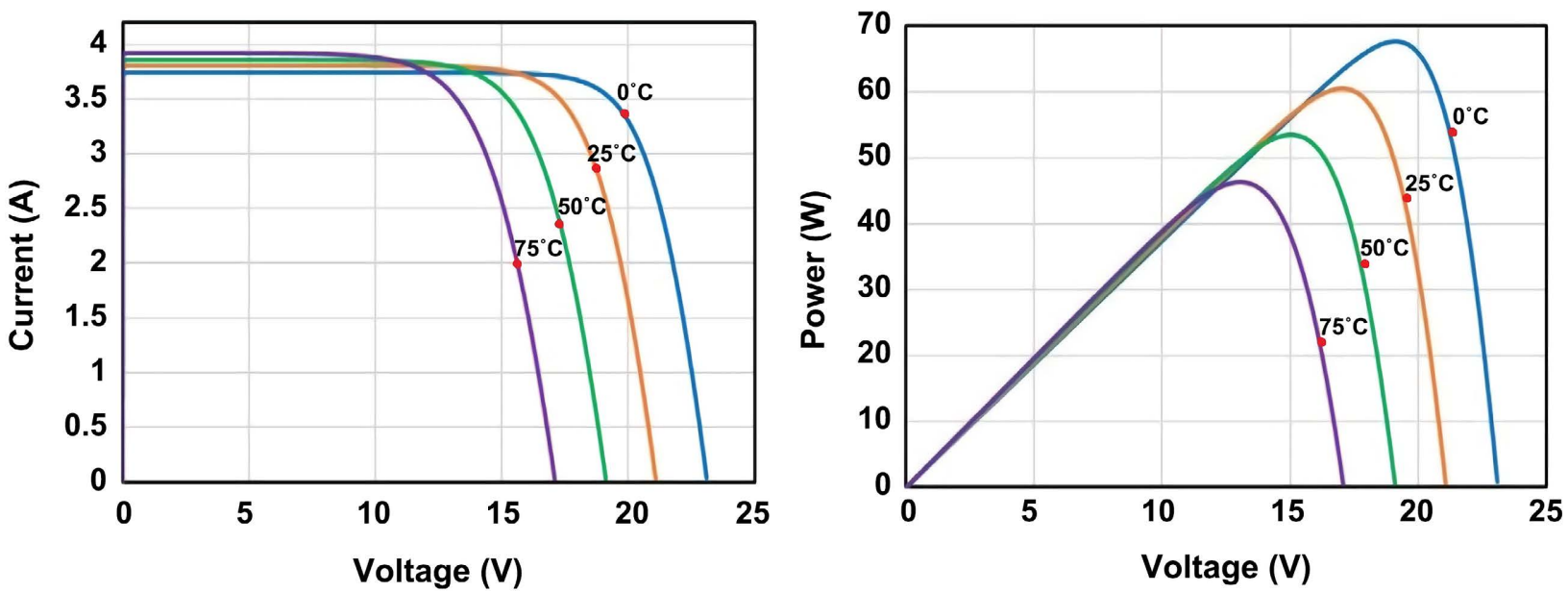

Figure 2. I-V and P-V characteristics for various values of temperature at $\mathrm{G}=1000 \mathrm{~W} / \mathrm{m}^{2}[4]$. 


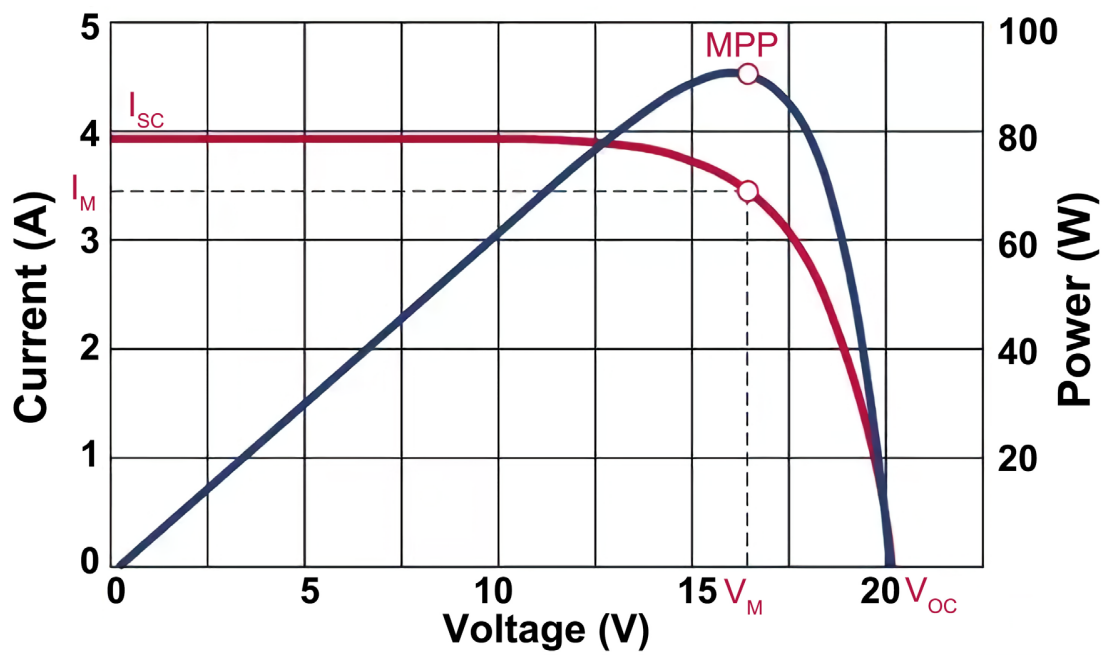

Figure 3. Maximum power point (MPP) curve [5].

The PV output also depends on operating point imposed by the load which was not indicated before [6]. As a result, an advanced control strategy is needed to maximize efficiency and generate and transfer as much power as possible from the photovoltaic cell to a load. The strategy matches the load resistance to the source (PV cell) resistance, forcing the PV cell to work on the MPP and ensuring optimum power extraction independent of ambient atmospheric conditions or load. This strategy called Maximum Power Point Tracking (MPPT). In addition, the PV system's operation using the MPPT method leads to supply high power output and therefore decreases the total number of PV cells needed, lowering the overall cost [3].

Many studies have carried out the field of the MPPT and especially the FLC method used in the low power of PV systems. Additionally, usually the MPPT is usually tested performance with the resistant load. In this study, the system will be a little different so that the PV system with about $60 \mathrm{KW}$ of power and the load will be Lithium-Ion battery. Furthermore the process of adding the output crisp value of the FLC to the previous value of duty ratio (D) before transfer to pulse width modulation (PWM) will be ignored.

The rest of this paper is organized as follows: Section 2 gives an introduction of MPPT and the most famous various existing methods available in the literature with their features, advantages and shortcomings. Section 3 demonstrates basic operation principles of previous and introduces the flowchart of the proposed FLC technique for MPPT controller. Section 4 describes how the Simulink model and software simulation can be implemented for a battery load fed from the PV system through MPPT based on FLC. Simulation results based on specific parameters of The PV system have been elaborated in Section 5. Finally, conclusions and a summary of the research work are presented in Section 6.

\section{MPPT Controller Methods}

The PV system contains a DC-DC converter to separate the generator running 
point (voltage and current) from the load, where this power converter is organized by an algorithm which lookup, online, for the point Maximum Power, this algorithm is called the Maximum Power Point Tracking (MPPT) [6].

Until now, there are several methods or algorithms of maximum power point tracking (MPPT) have been explored for use in photovoltaic systems. For most energy tracking systems, efficiencies higher than $90 \%$ were reported, making their use very appealing not only with medium to high power but also with low power PV systems [7]. The MPPT methods or algorithms that the most famous can be approximately classified, into two groups: there are conventional methods, such as the Incremental Conductance (IC) method, the Perturbation and Observation (P\&O) method and Ripple Correlation Control (RCC) method, and another group is evolving methods, such as, fuzzy logic control (FLC) based MPPT method, a neural network (ANN) and sliding mode control (SMC) algorithms [8] [9]. These methods, on the other hand, have flaws such as difficulty, high cost, complexity, and instability.

In [10] and [11] IC algorithm is able to pursue a quick oscillate of the solar irradiance with a great grade of accuracy. The complication and the high price of implementing this method are solely harmful factors. In the other classical P\&O algorithm the uncomplicatedness of its structure and simplicity of implementation are the good things. But this algorithm is not deprived of its particular downsides. Main downside happening is the failure of the algorithm to acclimate to fast varying atmospheric environments and there is moreover a losing power because of the constant perturbation variations entered. The last one of conventional methods (RCC) which is a more flexible, robust and high rate of convergence but not suitable for converters with dc loads, three-phase loads, or perhaps even noisy single-phase loads. It also needs a larger inductor to decrease the fluctuation of the voltage and power. If the fluctuation and gain are very high, the control can saturate and exhibition limit cycle performance. In additionally [12] [13] IC, P\&O and RCC methods usually require two sensors to measure module voltage and current which leads to increased losses of power.

With regard to intelligent or advanced groups which are more efficient than conventional methods, both ANN and FLC methods are faster convergence and show no oscillation at MMP. Those methods perform well under changing atmospheric conditions. But FLC is distinguished more efficient than ANN, robust, able to detect global MPP and do not need the knowledge of exact model. Demerits of ANN and FLC complexity, costs and requires periodic tuning. SMC method has high accuracy, steady state, simple and strong, but sluggish transient response and chattering are main drawbacks [11] [12].

Now some studies discussing comparisons between different MPPT methods will be presented briefly in the next paragraph.

In [14] study provides an analytical comparison for RCC, P\&O and IC at different irradiations. The simulation results show that $\mathrm{P} \& \mathrm{O}$ is greatly affected by slow tracking and fluctuations, and IC achieves better than P\&O in terms of tracking, but not for ripples. On the other hand, the RCC is able to solve both 
these shortcomings effectually which also is the best among the two P\&O and IC MPPT techniques on performance. Another study [15] discusses the comparison between P\&O and RCC. Summary of study results reached to that the RCC method has faster response and lower settling time compared to the $\mathrm{P} \& \mathrm{O}$. The rate of convergence of RCC is found to be greater than the P\&O. Abdelhakim et al. [16] investigate a wide ranging comparison between different photovoltaic MPPT techniques which are P\&O, IC, SMC, and FLC. The EN 50530 stander applied on proposal comparative MPPT method that was simulated by Matlab/Simulink. The EN 50530 is a rigorous profile based on fast changing climatic conditions. Five assessment criteria indicators make a complete comparison between these MPPTs. The criteria indicators are instant efficiency, steady state tracking accuracy, average efficiency, transient tracking accuracy and tracking time. The results showed that, in comparison with other techniques, FLC provides good performance in the steady-state as well as the dynamic response. Last study [17] makes a comparison of the conventional IC method and intelligent FLC method. The Matlab/Simulink simulation results show that FLC method has a good performance in the transient state and a weak fluctuation in steady state. The IC, however, has a huge fluctuation in steady state. The IC method is widely used, but the FLC is the best compatible and can extract maximum energy of the PV system, because of the membership functions of the FLC as compared to the IC algorithm.

Out of these MPPT methods some have low cost and complexity, but they also have lower efficiency, while others are expensive but efficient. It is hard to figure out which method is the best because it depends on the application and requirements each has its advantages and disadvantages. Anyway, it is clear from previous studies that FLC is suitable to achieve MPPT for PV systems because FLC is robust, comparatively easy to build, and does not need knowledge of the PV exact model. FLC is also suitable for non-linear control and has more stability which good requirement to increase battery life. Furthermore, FLC does not make use of intricate mathematics. So that FLC was chosen and used to monitor the Maximum Power Point (MPP) of a PV module in this work.

\section{MPPT Using Fuzzy Logic Controller}

The maximum power point monitoring devices are used by the $\mathrm{dc}$ to $\mathrm{dc}$ converters to indemnity the output voltage of the solar panel in order to maintain the voltage at the value that maximizes the output power. The conceptual fuzzy MPP controller calculates the power from the equation $(P=V \times I)$ to extract the controller inputs with voltage after measuring the voltage and current at the solar panel output. The waveform of the duty cycle of the PWM used to toggle the dc to dc converter is represented by the fuzzy controller's wavy output [18].

The concept principal of MPPT Fuzzy Logic Controller as follows. The output power of PV is examined by the FLC in each sample (Time_k) and then defines the change in power with respect to voltage $(\mathrm{d} p / \mathrm{d} v)$. If this value $(\mathrm{d} p / \mathrm{d} v)$ is big- 
ger than zero, the controller modifies the pulse width modulation (PWM) duty cycle to increase the voltage until the power is maximum or the value $(\mathrm{d} p / \mathrm{d} v)=$ 0 , if this value is lower than zero the controller changes the PWM service cycle to reduce the voltage until the power is maximum and so on. Figure 4 illustrated that.

FLC has two inputs that are: error and change of error, as well as an output feeding the modulation of pulse width to control the DC-DC converter. The input signals depend on the instantaneous power and output voltage values which in turn effected by ambient atmospheric like radiation and temperature. The two FLC input variables error $(E(k))$ and change of error $(\Delta E(k))$ at sampled times $k$ are calculated by [20]:

$$
\begin{aligned}
& E(k)=\frac{P(k)-P(k-1)}{V(k)-V(k-1)} \\
& \Delta E(k)=E(k)-E(k-1)
\end{aligned}
$$

where $P(k)$ and $V(k)$ are the instant power and voltage respectively of the PV generator.

The input $E(k)$ point to whether the load running point in moment $k$ is to the left or right of power-voltage characteristic's maximum power point for the PV module, whereas the input $\Delta E(k)$ specifies the trend of movement of that point. Mamdani process of FLC for the MPPT, is utilized to perform the fuzzy inference. Fuzzification, inference engine, and defuzzification are the three essential components for FLC as shown in Figure 5 [9] [21].

\subsection{Fuzzification}

In Fuzzification process, the error $E(k)$ and change of error $\Delta E(k)$ input variables are converted into linguistic variables as fuzzy inputs using a membership function such as LP (large positive), MP (medium positive), SP (small positive),

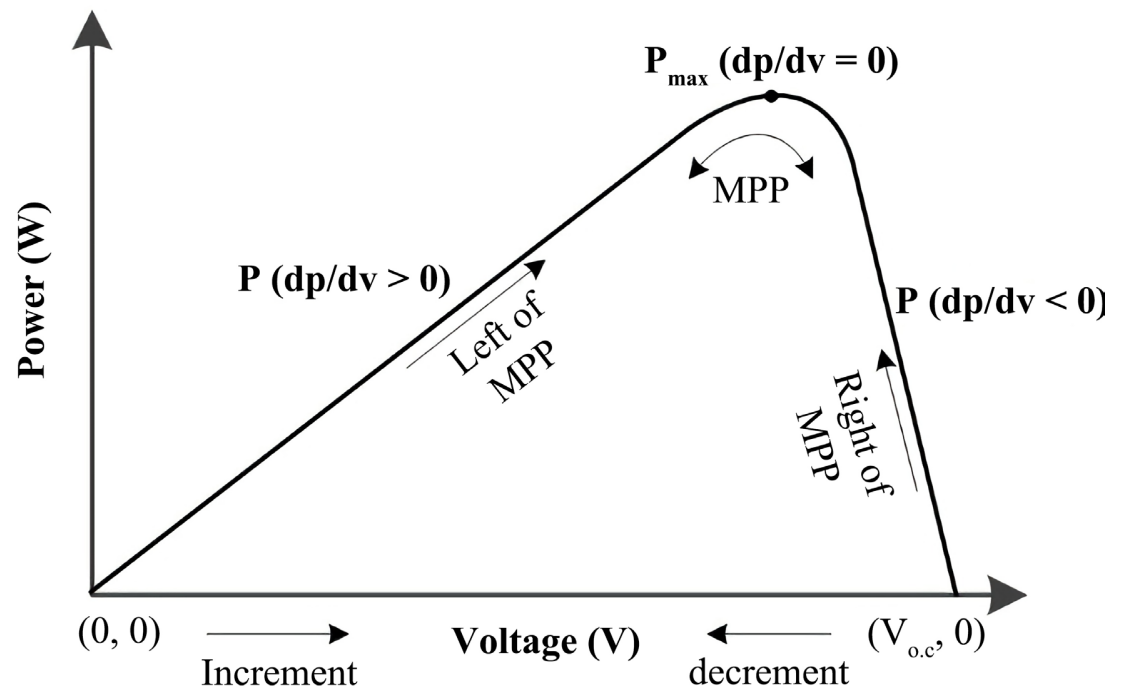

Figure 4. The concept principal of MPPT fuzzy logic controller [19]. 


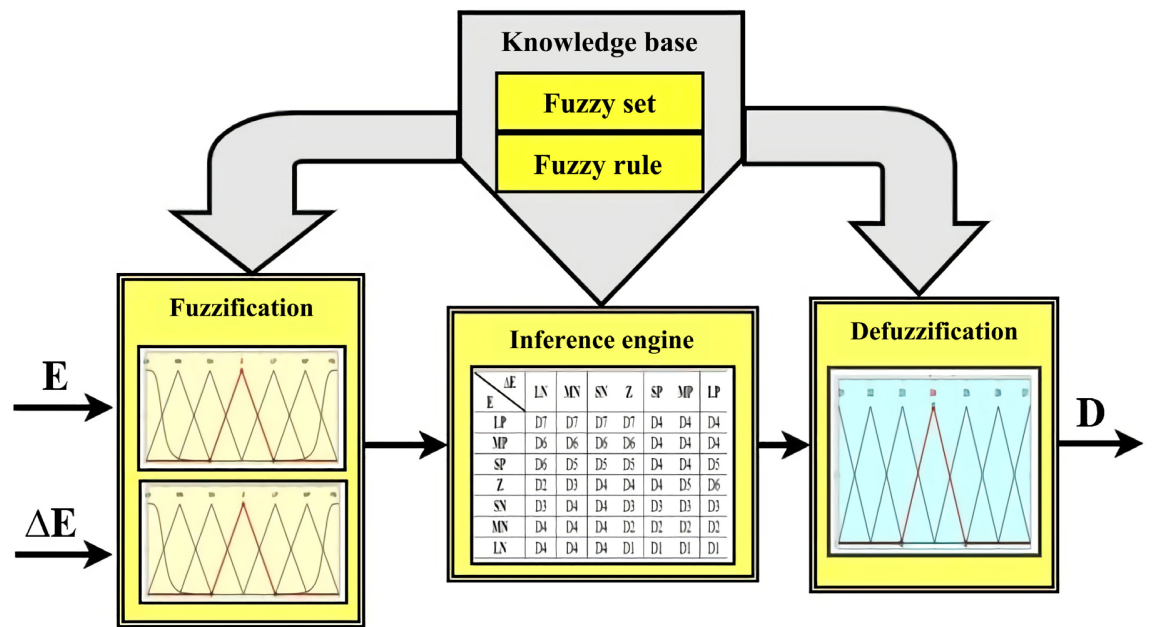

Figure 5. Construction of FLC for MPPT.

$\mathrm{Z}$ (zero), SN (small negative), MN (medium negative) and LN (large negative), and D1...D7 for output that proposed for FLC in this work.

\subsection{Inference Engine}

Mandamni's method, which implements a rule to the fuzzy input to define the fuzzy output, is used to determine the fuzzy inference engine. To get an acceptable linguistic value, the actual input value must be fuzzified before the rule can be evaluated. Table 1 displays the fuzzy controller rules list, with all matrix entries being fuzzy sets of the inputs $E(k), \Delta E(k)$ and the output the duty ratio $(D)$ to converter. Table 1 contains 49 fuzzy controller rules in its ruleset. These rules are used to monitor the DC to DC converter and ensure that the PV module's MPP is met. An inference mechanism evaluates the control rules, which are interpreted as a set of:

IF $E(k)$ is...and $\Delta E$ is...Then the output $(D)$ is...

For example: Rule1: IF $E(k)$ is $\mathrm{LN}$ and $\Delta E$ is LP. Then the output $(D)$ is D7.

The main goal of the rules is to make the PV module's operation point closer to the MPP by increasing or decreasing the duty ratio of the DC to DC Converter based on the operation point's location from the MPP [20] [22].

\subsection{Defuzzification}

In [22] the fuzzy controller output must be transformed from fuzzy information to peremptory information because the buck converter needs a specific D-control signal when it enters. Defuzzification is the term for this transformation. The fuzzy logic controller output is transformed from a linguist variable to a mathematical variable during the Defuzzification stage. Defuzzification can be done using a variety of algorithms, including Center of Area (COA), Center of Gravity (COG), or the Max Criterion Method (MCM). The determination of the fuzzy combined final set's center of gravity (COG) is the most widely used form of Defuzzification. Using the maximum aggregation process, the last combined 
Table 1. Fuzzy rules control based on relationship of membership function.

\begin{tabular}{cccccccl}
\hline$E / \Delta E$ & LN & MN & SN & Z & SP & MP & LP \\
\hline LP & D7 & D7 & D7 & D7 & D4 & D4 & D4 \\
MP & D6 & D6 & D6 & D6 & D4 & D4 & D4 \\
SP & D6 & D5 & D5 & D5 & D4 & D4 & D5 \\
Z & D2 & D3 & D4 & D4 & D4 & D5 & D6 \\
SN & D3 & D4 & D4 & D3 & D3 & D3 & D3 \\
MN & D4 & D4 & D4 & D2 & D2 & D2 & D2 \\
LN & D4 & D4 & D4 & D1 & D1 & D1 & D1 \\
\hline
\end{tabular}

fuzzy set is described by combining all outputs from the fuzzy set of laws. The gravity center $(D)$ is determined using the formula [20]:

$$
D=\frac{\sum_{j=1}^{n} \mu\left(\Delta D_{j}\right) \times \Delta D_{j}}{\sum_{j=1}^{n} \mu\left(\Delta D_{j}\right)}
$$

where $D$ is the crisp value output value, $\Delta D_{j}$ is the center of max-min composition at the output MFs, $\mu\left(\Delta D_{j}\right)$ is the maximum of the th membership function, $D_{j}$ is the $t$ th input value.

Some of the studies suggest a process that before transfer of the crisp value $(D)$ to the MOSFET's gate by adding it to the previous value of duty ratio. On the other hand in this study, the crisp value $(D)$ is transferred to IGBT's gate without doing that process and the FLC work very well. The flowchart of FLC for MPPT is shown in Figure 6.

\section{PV Module with MPPT Based FLC Simulate via Matlab/Simulink}

Figure 7 shows the basic diagram of an MPPT based on FLC. It is clear from the observation that the state's only two variables are viewed as fuzzy controller inputs: $\left(V_{m}\right)$ and $\left(I_{m}\right)$, which are the PV module's output voltage and current output. A signal proportional to the converter duty cycle $(D)$ is fed to the converter by a PWM, which is produced by the fuzzy logic controller based on measurements. This modulator generates the $D$ value for PWM, which generates the control signals for the converter switch (s). A closed loop system is characterized by the fuzzy logic controller diagram [24].

\subsection{PV Modelling for Simulation}

The PV modeling system to generate power by PV array block are by Matlab/Simulink which has several parameters, a graphical user interface (GUI) has been created to insert the data of any array model by entering parameters from its datasheet or by selecting available PV modules in GUI as shown in Figure 8. Module PV of SunPower SPR-343J-WHT-D was chosen for this study [25]. 


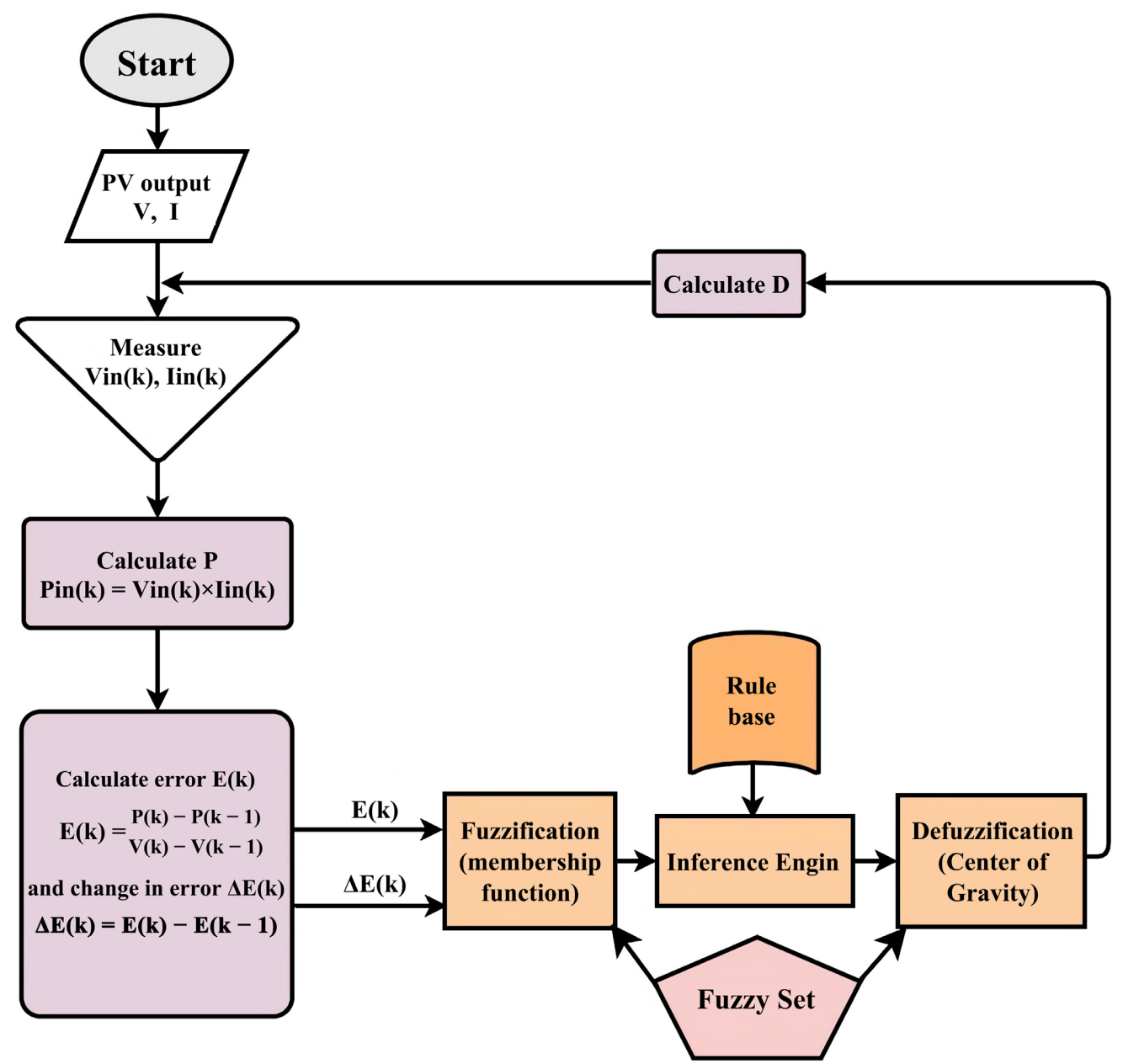

Figure 6. Flowchart of fuzzy logic control for MPPT [23].

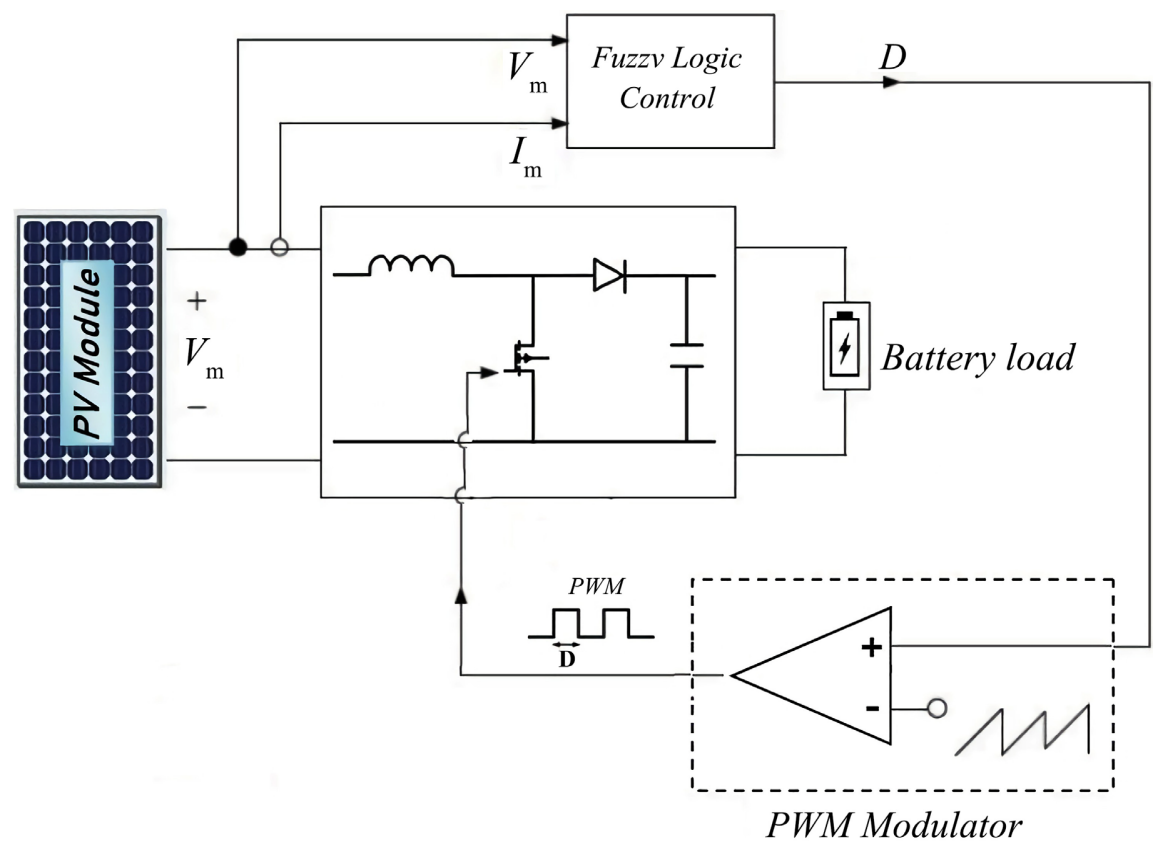

Figure 7. Fuzzy control scheme for a maximum power point tracker. 


\begin{tabular}{|c|c|c|c|}
\hline \multicolumn{4}{|l|}{ PV array (mask) (link) } \\
\hline \multicolumn{4}{|c|}{$\begin{array}{l}\text { Implements a PV array built of strings of PV modules connected in parallel. Each string consists } \\
\text { Allows modeling of a variety of preset PV modules available from NREL System Advisor Model (Ja } \\
\text { Input } 1 \text { = Sun irradiance, in W/m2, and input } 2 \text { = Cell temperature, in deg.C. }\end{array}$} \\
\hline \multicolumn{4}{|l|}{ Parameters Advanced } \\
\hline \multicolumn{2}{|l|}{ Parallel strings 22} & \multicolumn{2}{|l|}{ array @ 25 deg.C \& specifled irradlances } \\
\hline & Irradiances (W/m2) [ [ [ llll $\left.\begin{array}{lll}1000 & 600 & 200\end{array}\right]$ & : \\
\hline Series-connected modules per string 8 & $\vdots$ & \multicolumn{2}{|l|}{ Plot } \\
\hline \multicolumn{2}{|l|}{ Module data } & \multicolumn{2}{|l|}{ Model parameters } \\
\hline Cells per module (Ncell) 96 & i & \multirow[t]{2}{*}{ Diode saturation current I0 (A) $1.3957 \mathrm{e}-11$} & i \\
\hline \multicolumn{2}{|l|}{ Open circuit voltage $\operatorname{Voc}(\mathrm{V}) 68.11$} & & \\
\hline \multicolumn{2}{|l|}{ Short-circuit current Isc (A) 6.37} & \multirow[t]{2}{*}{ Diode ideality factor 1.0293} & i \\
\hline Voltage at maximum power point $\mathrm{Vmp}(\mathrm{V})$ & 57.3 & & \\
\hline Current at maximum power point $\operatorname{Imp}(\mathrm{A})$ & 5.99 & \multicolumn{2}{|l|}{ Shunt resistance Rsh (ohms) 542.7076} \\
\hline Temperature coefficient of Voc (\%/deg.C) & -0.291 & \multirow[b]{2}{*}{ Series resistance Rs (ohms) 0.4804} & \\
\hline Temperature coefficlent of Isc (\%/deg.C) & 0.013297 & & \\
\hline
\end{tabular}

Figure 8. GUI for entering the parameters of PV array model.

\subsection{Control Signal Generation MPPT in Simulation}

Figure 9 illustrates how the Equations (1) and (2) are represented in Matlabe program, to engender the $E(k)$ and $\Delta E(k)$ signals as entries for the FLC.

\subsection{Fuzzy Logic Controller for MPPT Simulation}

The two inputs are the Error $(E)$ and Change in Error (CE) signals, which are processed to calculate the duty ratio output $(D)$ of this FLC. The fuzzy logic algorithm was simulated using the fuzzy logic toolbox in Simulink/Matlab, and the rules were fine-tuned. In Figure 10, the basic window of the fuzzy designer is shown, with the controller based on Mamdani's fuzzy inference method and the centroid method as a defuzzification mechanism.

\subsection{Membership Functions of the Proposed Fuzzy System}

Fuzzy sets for each input and output variable that is defined triangular and generalized bell shapes have been adopted for the seven fuzzy subsets membership functions; LN (large negative), MN (medium negative), SN (small negative), Z (zero), SP (small positive), MP (medium positive) and LP (large positive) were chosen for the fuzzy controller's input and output variables. As shown in Figure 11.

\subsection{Batteries}

Most PV systems during non-daylight hours, times of heavy cloud cover or elec- 
trical vehicle fast charge station that need some form of battery to power the system. So the battery use as the load for simulation (see Figure 12).

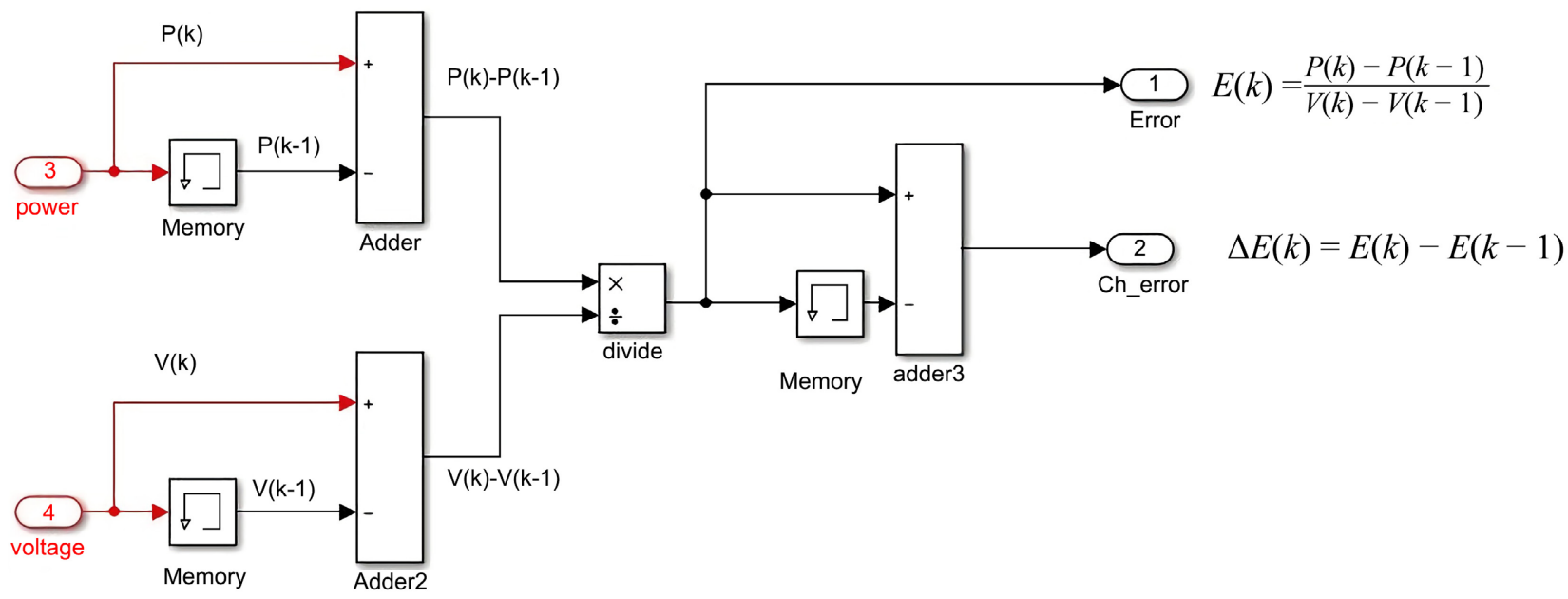

Figure 9. Constructive generating of the error and change in error equations.

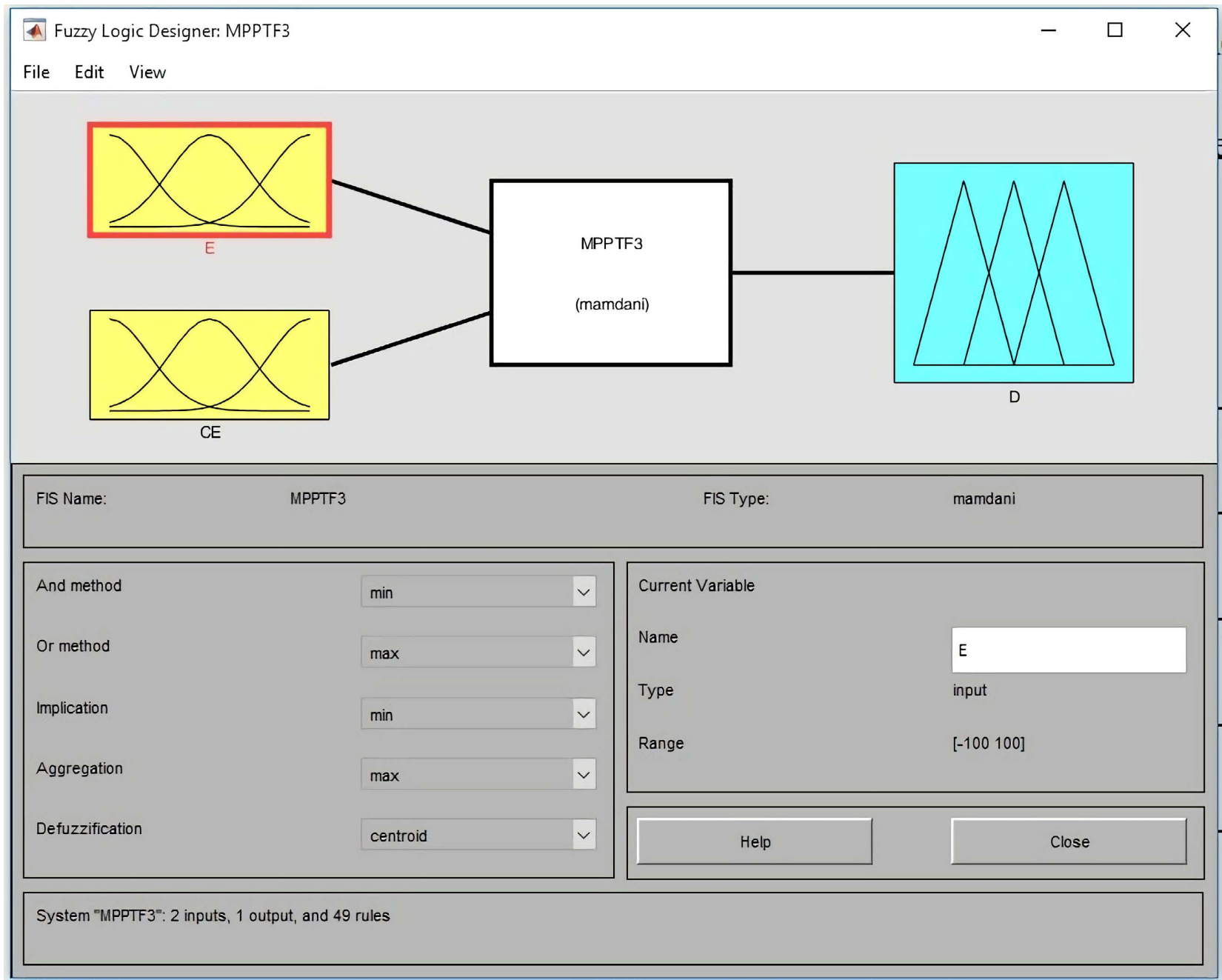

Figure 10. Fuzzy logic designer in Matlab tool box. 


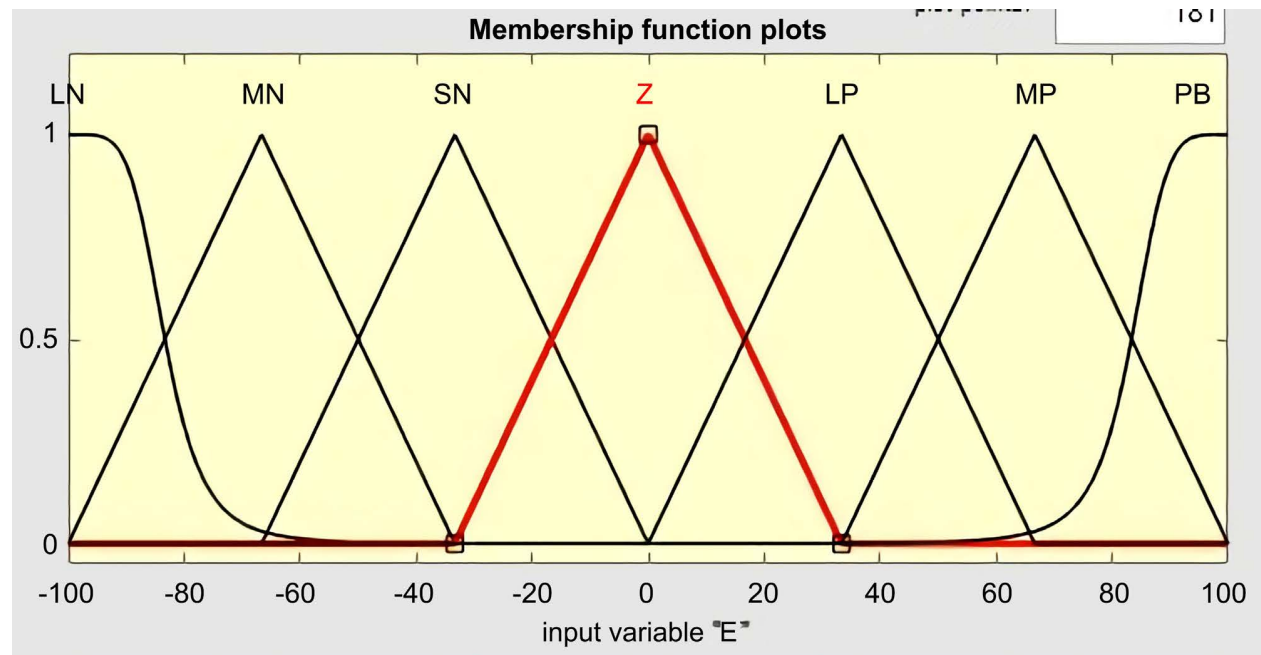

(a)

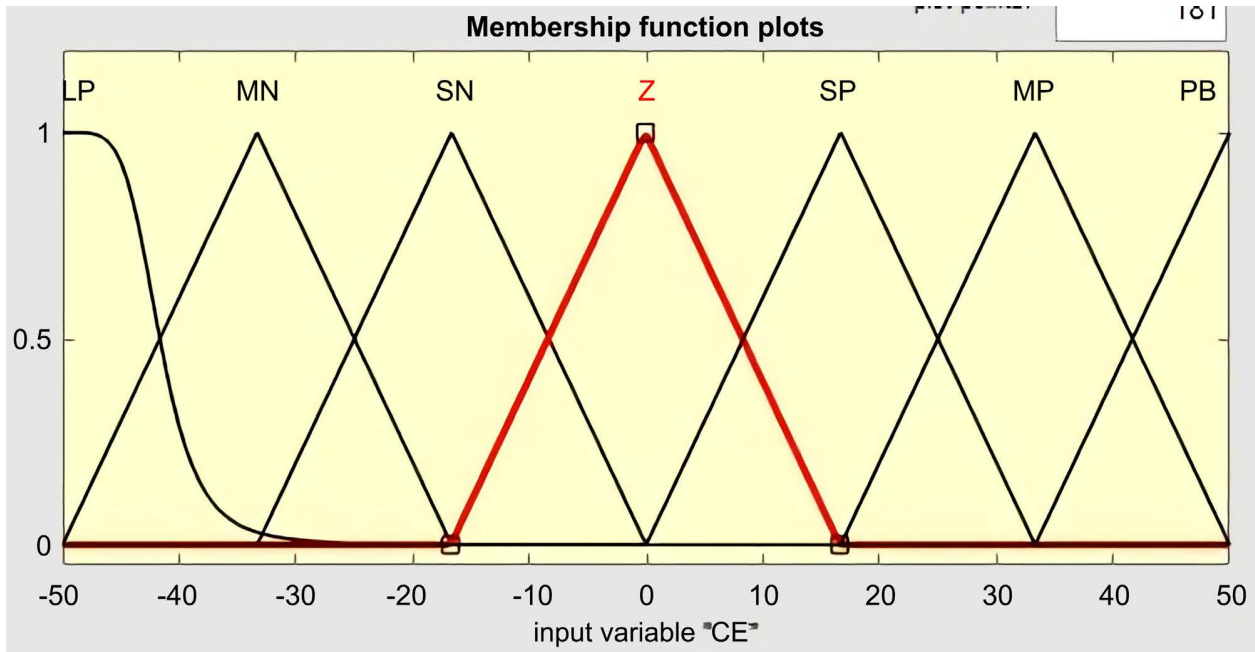

(b)

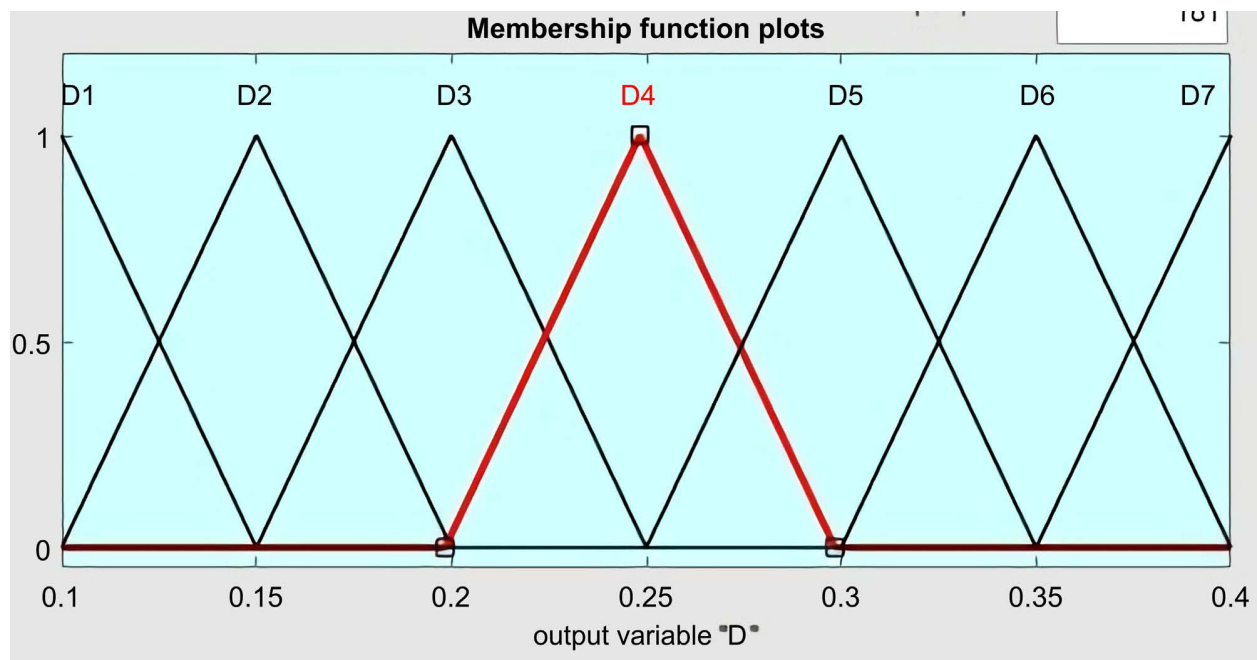

(c)

Figure 11. Membership functions for (a) input error (b) input change in error (c) output duty cycle of fuzzy controller. 


\section{Computer Simulation and Results}

The values of the parameters used for simulation are presented in Table 2.

The entire system was combined and tested in Simulink/Matlab for change values of solar irradiation and temperature by using signal builder with ramp function carve (as shown in Figure 13).

The simulation model shown in Figure 14 was implemented at Simulink/ Matlab at different changes of irradiance and temperature use signal builder with ramp function carve. In order to check the fuzzy controller performance and the efficiency of the converter the readings of input and output power of the MPPT were taken at solar irradiance $\left(1000 \mathrm{w} / \mathrm{m}^{2}, 600 \mathrm{w} / \mathrm{m}^{2}\right)$ and temperature $\left(25^{\circ} \mathrm{C}, 45^{\circ} \mathrm{C}\right)$ and also other measurements.

Figures from (Figures 15-19) show the curves of the result simulation of PV

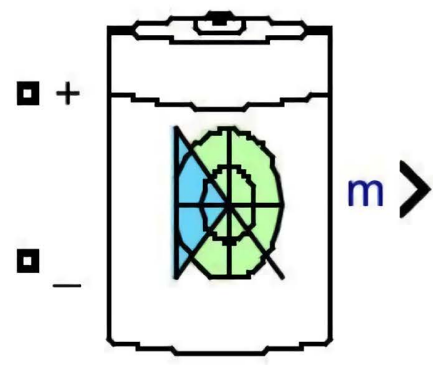

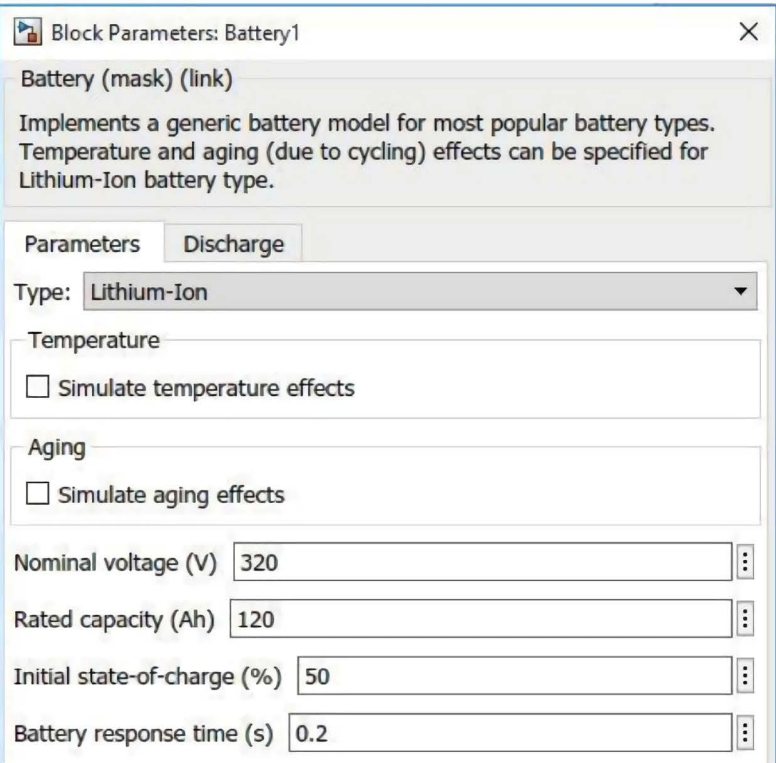

Figure 12. Battery modal and block parameters in Matlab Simulink.

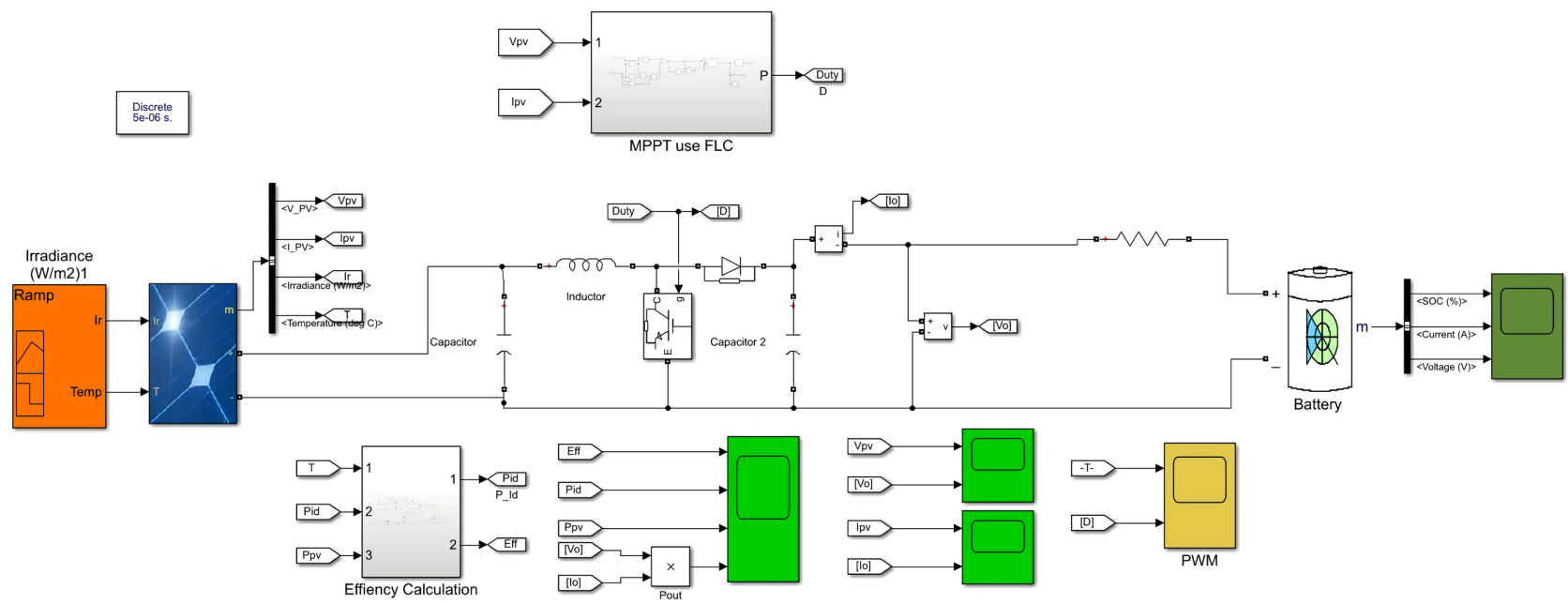

Figure 13. PV system simulation based maximum power point tracking of photovoltaic using FLC. 
Table 2. Design parameter.

\begin{tabular}{cccccc}
\hline \multicolumn{2}{c}{ PV Array } & \multicolumn{2}{c}{ Boost converter } & \multicolumn{2}{c}{ Battery } \\
\hline Parameters & Value & Parameters & Value & Parameters & Value \\
\hline$P_{p v} \max (\mathrm{KW})$ & 60.4 & Output capacitor Cin $(\mu \mathrm{F})$ & 100 & State of Charge (SOC) & 50 \\
$V_{o c}(\mathrm{~V})$ & 544.88 & Inductance $(\mathrm{H})$ & $21 \mathrm{e}-3$ & $(\%)$ & \\
$I_{s c}(\mathrm{~A})$ & 140.1 & Intput capacitor Cin $(\mu \mathrm{F})$ & 2000 & Nominal voltage $(\mathrm{V})$ & 320 \\
$V_{m p}(\mathrm{~V})$ & 458.4 & Switch Frequency PWM & 50 & Capacity (Ah) & 120 \\
$I_{m p}(\mathrm{~A})$ & 131.37 & $(\mathrm{KHz})$ & & Charge voltage $(\mathrm{v})$ & 350 \\
\hline
\end{tabular}

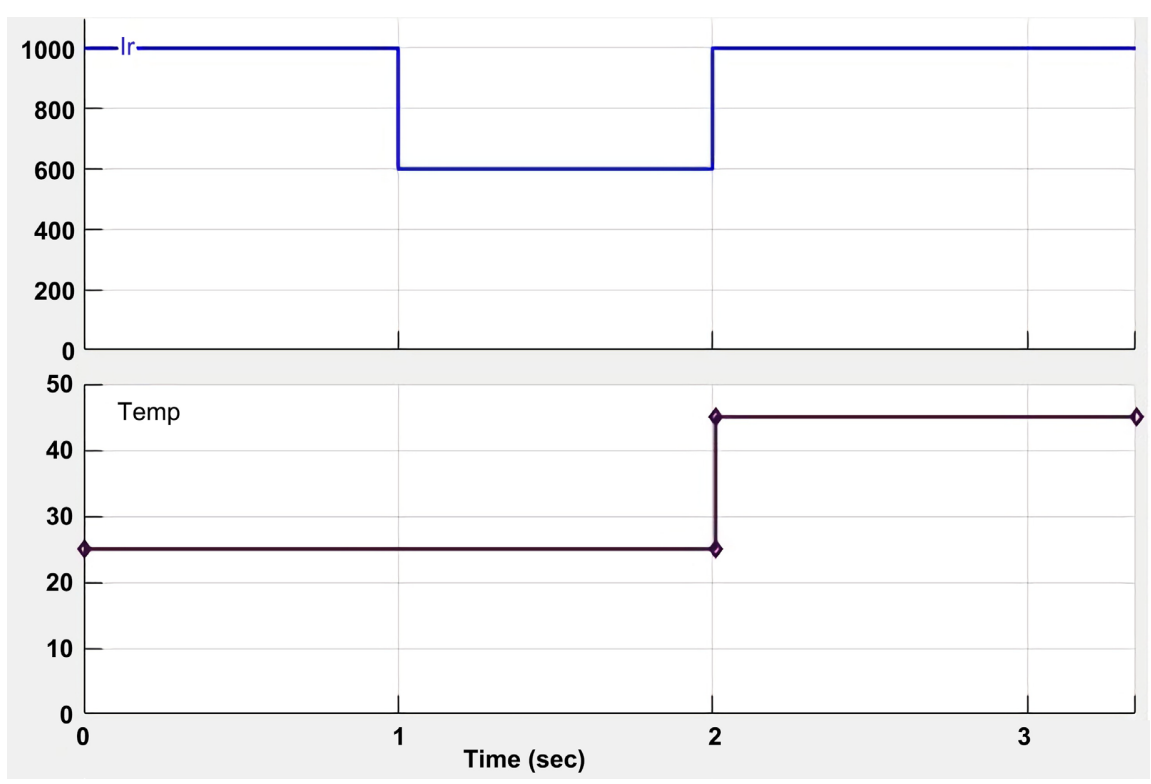

Figure 14. Change values of solar irradiation and temperature.

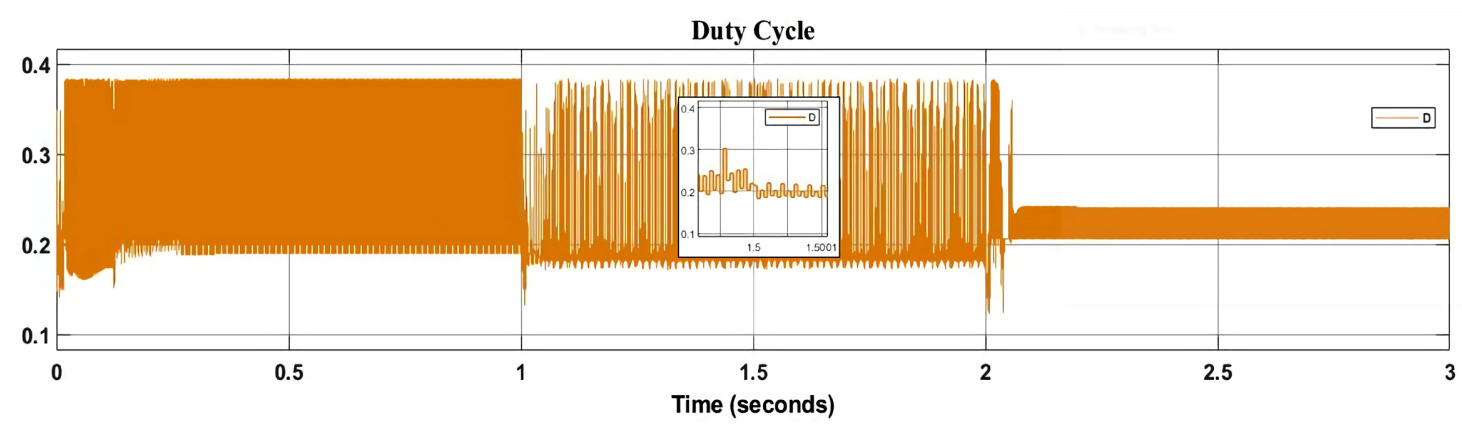

Pulse-width modulation

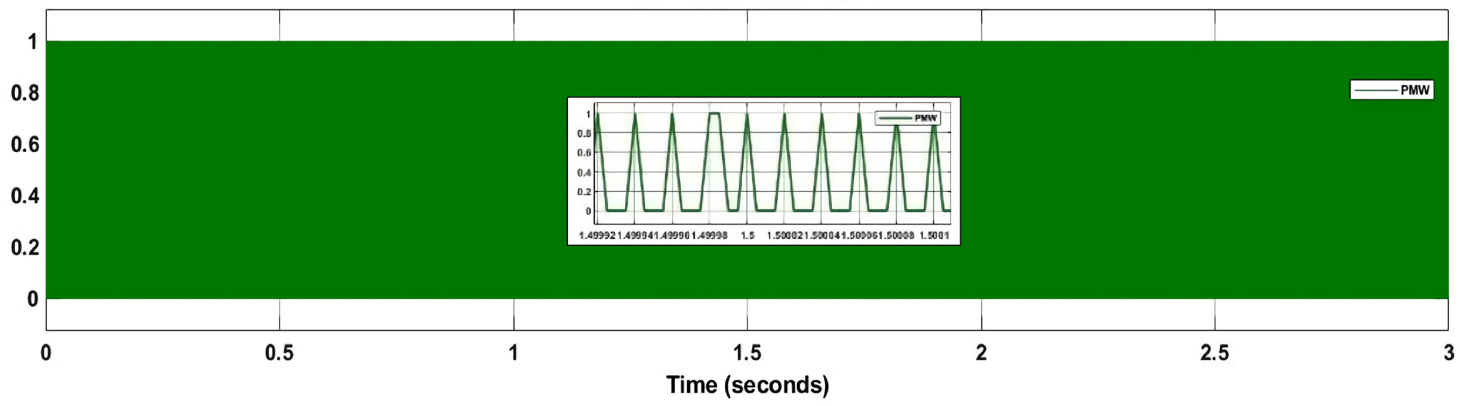

Figure 15. Fuzzy duty cycle output and PWM. 

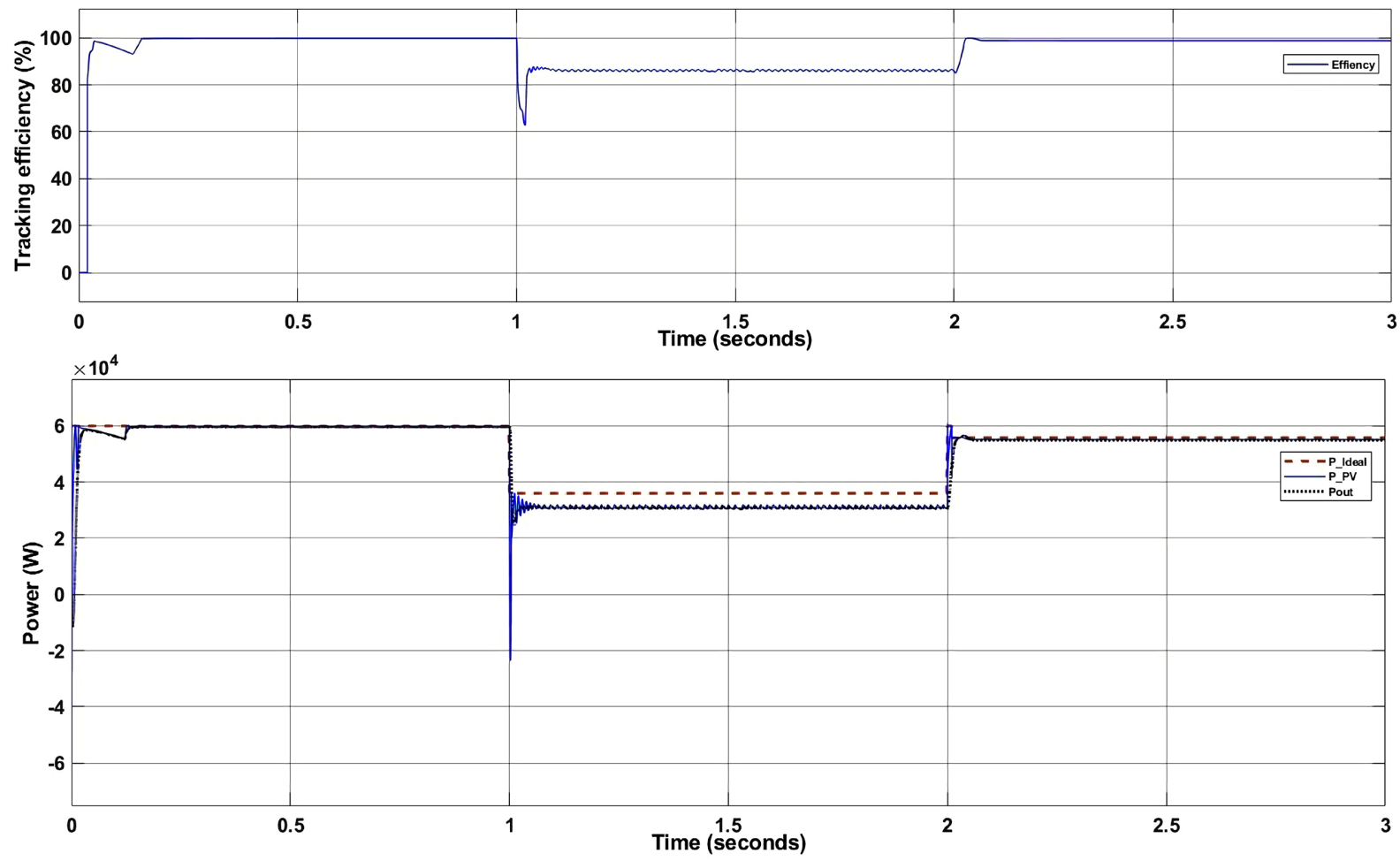

Figure 16. PV power, output power, Ideal power and efficacy.

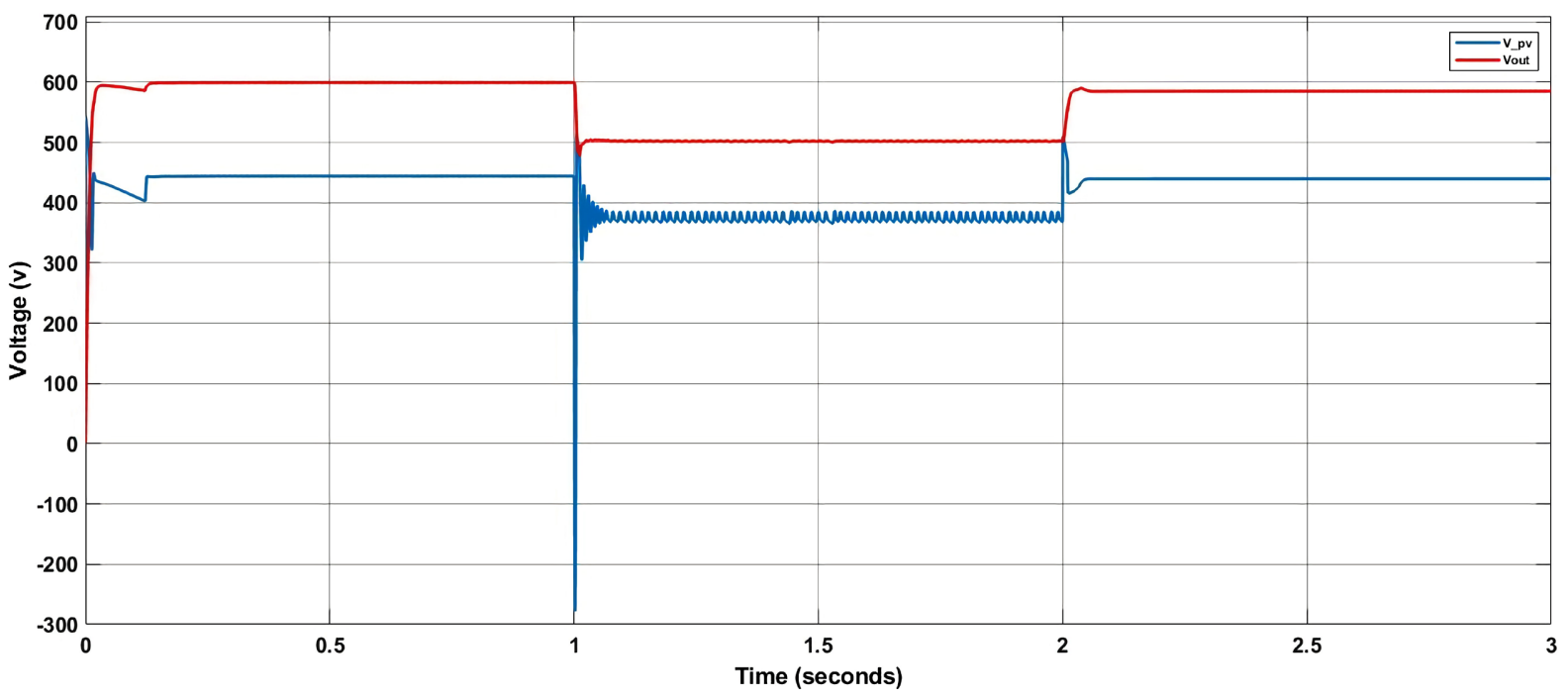

Figure 17. PV voltage and output voltage.

Table 3. Simulation results of PV system simulation based of FLC MPPT.

\begin{tabular}{|c|c|c|c|c|c|c|c|c|c|c|c|c|}
\hline \multirow{2}{*}{$\begin{array}{c}\text { PERIOD } \\
\begin{array}{c}\text { Time } \\
(\mathrm{sec})\end{array}\end{array}$} & \multicolumn{2}{|c|}{ SOLAR } & \multicolumn{4}{|c|}{ POWER } & \multicolumn{2}{|c|}{ VOLTAGE } & \multicolumn{2}{|c|}{ CURRENT } & \multicolumn{2}{|c|}{ BATTERY CHARGE } \\
\hline & $\begin{array}{c}\text { IR } \\
\left(\mathrm{W} / \mathrm{m}^{2}\right)\end{array}$ & $\begin{array}{c}\text { Temp } \\
\left({ }^{\circ} \mathrm{C}\right)\end{array}$ & $\begin{array}{c}\text { P_ideal } \\
(\mathrm{KW})\end{array}$ & $\begin{array}{l}\text { P_pv } \\
(\mathrm{KW})\end{array}$ & $\begin{array}{l}\text { Pout } \\
\text { (KW) }\end{array}$ & $\begin{array}{l}\text { Eff } \\
(\%)\end{array}$ & $\begin{array}{l}\text { V_pv } \\
\text { (V) }\end{array}$ & $\begin{array}{l}\text { Vout } \\
\text { (V) }\end{array}$ & $\begin{array}{l}\text { I_pv } \\
\text { (A) }\end{array}$ & $\begin{array}{l}\text { Iout } \\
\text { (A) }\end{array}$ & $\begin{array}{l}\text { V_bat } \\
\text { (V) }\end{array}$ & $\begin{array}{l}\text { I_bat } \\
\text { (A) }\end{array}$ \\
\hline $0-1$ & 1000 & 25 & 60 & 59.75 & 59.42 & 99.22 & 442 & 599 & 135 & 99 & 350 & -99 \\
\hline $1-2$ & 600 & 25 & 36 & 31.9 & 30.81 & 86.1 & 385 & 502 & 83 & 61 & 348 & -61 \\
\hline $2-3$ & 1000 & 45 & 55.8 & 54.6 & 54.28 & 97.85 & 401 & 583 & 136 & 93 & 350 & -93 \\
\hline
\end{tabular}




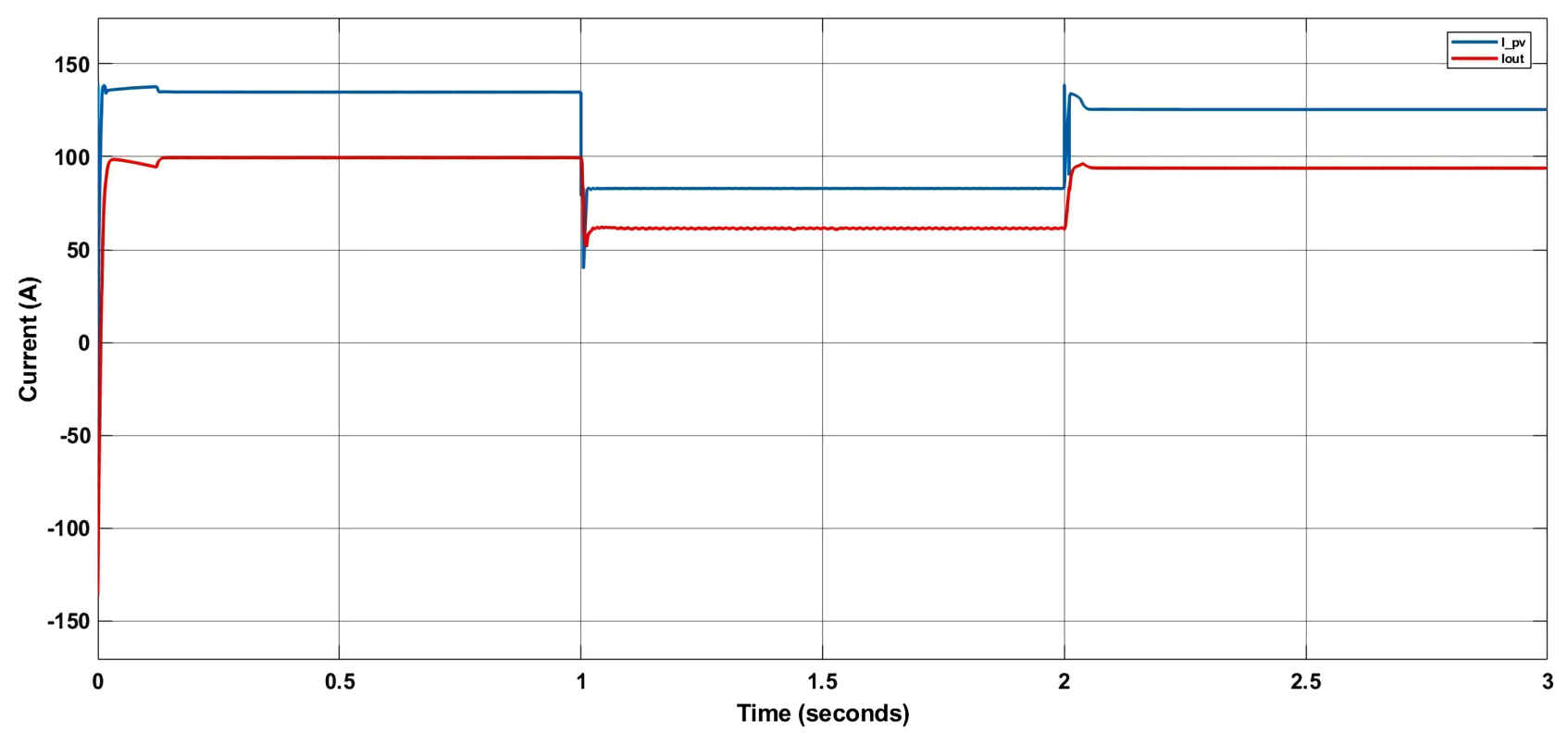

Figure 18. PV current and output current.
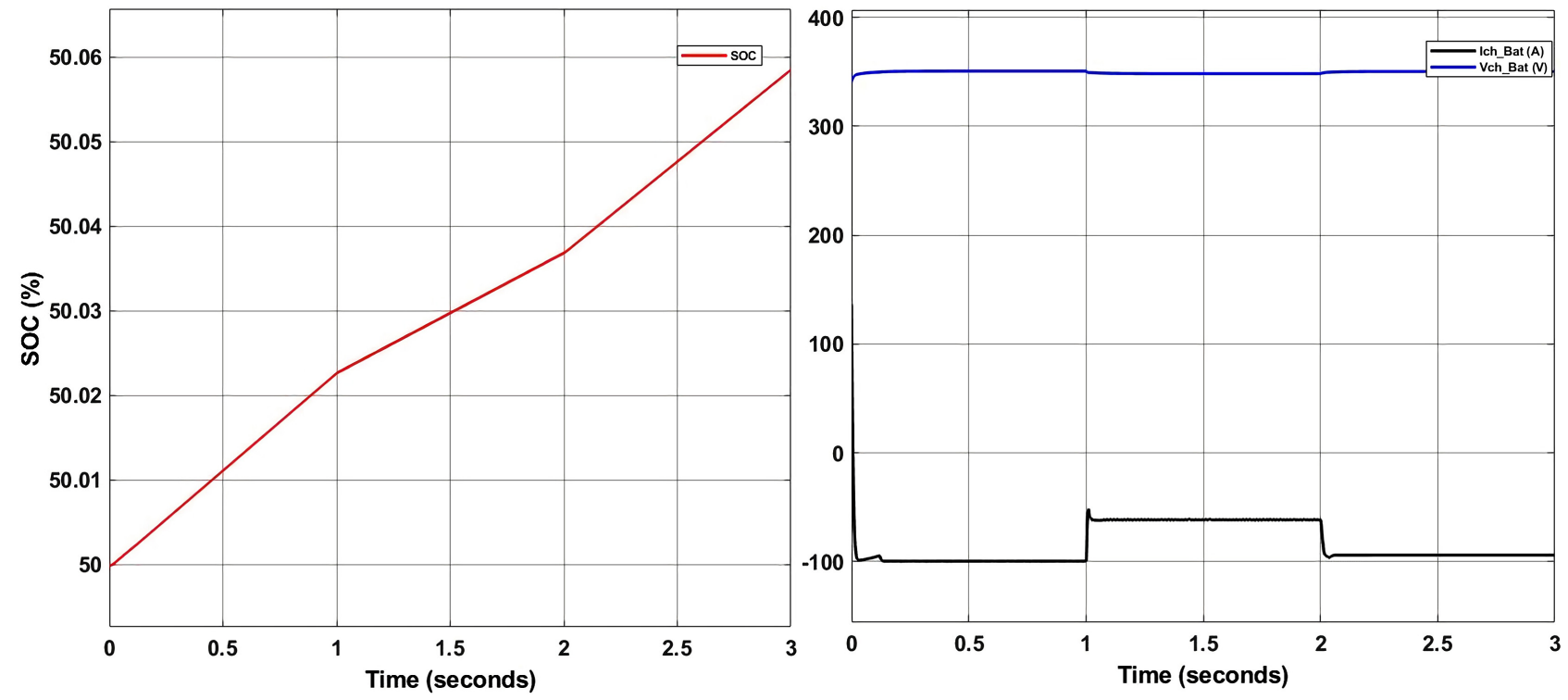

Figure 19. State of charge (SOC) and voltage, current charge of batter.

system based maximum power point tracking of photovoltaic using FLC. Table 3 illustrates details about simulation results.

\section{Conclusion}

This paper suggested a PV modeling system with a fuzzy controller for tracking the maximum power point of a photovoltaic source, which was then simulated in Simulink/Matlab. The fuzzy system's basic structures blocks were used to create the controller (Fuzzification, Inference and Defuzzification). These blocks read fuzzy inputs and program the plant's operation. The program then converts them into output action. The membership functions of the inputs and outputs 
have been proposed in triangular and generalized bell shapes in this controller, and the Mamdani fuzzy inference method and the centroid method as the Defuzzification procedure have also been chosen for this controller. PV, boost converter, fuzzy controller, and battery charge have all been modeled and simulated in response to irradiance and temperature changes. The results indicate that the proposed fuzzy controller for MPPT works well with about $94 \%$ tracking efficiency. Furthermore, for an MPPT of the PV system with battery load, FLC provides high performance because it has low settling time and limited steady state oscillation. These are assistant factors for extending battery life. So the system is suitable for use in real-time systems. As a future work we aim at developing the system model, and making it more appropriate with the application in life, fast charge stations for electrical vehicles are proposed as future work and integrate the renewable energy sources with the utility grid.

\section{Acknowledgements}

This research is funded by the Researchers Supporting Project number (RSP-2021/ 307), King Saud University, Riyadh, Saudi Arabia.

\section{Conflicts of Interest}

The authors declare no conflicts of interest regarding the publication of this paper.

\section{References}

[1] Lay-Ekuakille, A., Vergallo, P., Arnesano, A., Morello, R. and De Capua, C. (2013) Effects of Environmental Conditions on Photovoltaic Module Measurements. 2013 Seventh International Conference on Sensing Technology, Wellington, 3-5 December 2013, 933-936. https://doi.org/10.1109/ICSensT.2013.6727786

[2] Panagea, I.S., Tsanis, I.K., Koutroulis, A.G. and Grillakis, M.G. (2014) Climate Change Impact on Photovoltaic Energy Output: The Case of Greece. Advances in Meteorology, 2014, Article ID: 264506. https://doi.org/10.1155/2014/264506

[3] Khan, R., Khan, L., Ullah, S., Sami, I. and Ro, J.S. (2020) Backstepping Based Super-Twisting Sliding Mode MPPT Control with Differential Flatness Oriented Observer Design for Photovoltaic System. Electronics, 9, Article ID: 1543. https://doi.org/10.3390/electronics9091543

[4] Motahhir, S., El Hammoumi, A. and El Ghzizal, A. (2018) Photovoltaic System with Quantitative Comparative between an Improved MPPT and Existing INC and P\&O Methods under Fast Varying of Solar Irradiation. Energy Reports, 4, 341-350. https://doi.org/10.1016/j.egyr.2018.04.003

[5] Zischke, D. (2017) Maximum Power Point Tracking. https://bluesat.com.au/maximum-power-point-tracking/

[6] Ortiz Valencia, P.A. and Ramos-Paja, C.A. (2015) Sliding-Mode Controller for Maximum Power Point Tracking in Grid-Connected Photovoltaic Systems. Energies, 8, 12363-12387. https://doi.org/10.3390/en81112318

[7] Abou El Ela, M. and Roger, J.A. (1984) Optimization of the Function of a Photovoltaic Array Using a Feedback Control System. Solar Cells, 13, 107-119. 
https://doi.org/10.1016/0379-6787(84)90002-4

[8] Bendib, B., Belmili, H. and Krim, F. (2015) A Survey of the Most Used MPPT Methods: Conventional and Advanced Algorithms Applied for Photovoltaic Systems. Renewable and Sustainable Energy Reviews, 45, 637-648. https://doi.org/10.1016/j.rser.2015.02.009

[9] Anurag, A., Bal, S., Sourav, S. and Nanda, M. (2016) A Review of Maximum Power-Point Tracking Techniques for Photovoltaic Systems. International Journal of Sustainable Energy, 35, 478-501. https://doi.org/10.1080/14786451.2014.918979

[10] Jayakumaran, T., et al., (2018) A Comprehensive Review on Maximum Power Point Tracking Algorithms for Photovoltaic Cells. 2018 International Conference on Computation of Power, Energy, Information and Communication, Chennai, 28-29 March 2018, 343-348. https://doi.org/10.1109/ICCPEIC.2018.8525191

[11] Joshi, P. and Arora, S. (2017) Maximum Power Point Tracking Methodologies for Solar PV Systems-A Review. Renewable and Sustainable Energy Reviews, 70, 1154-1177. https://doi.org/10.1016/j.rser.2016.12.019

[12] Urayai, C. and Amaratunga, G.A.J. (2013) Single-Sensor Maximum Power Point Tracking Algorithms IET Renewable Power Generation, 7, 82-88.

https://doi.org/10.1049/iet-rpg.2011.0264

[13] De Brito, M.A.G., Junior, L.G., Sampaio, L.P., Melo, G.A.E. and Canesin, C.A. (2011) Main Maximum Power Point Tracking Strategies Intended for Photovoltaics. XI Brazilian Power Electronics Conference, Natal, 11-15 September, 524-530. https://doi.org/10.1109/COBEP.2011.6085188

[14] Sahu, P., Sharma, A. and Dey, R. (2020) Ripple Correlation Control Maximum Power Point Tracking for Battery Operated PV Systems: A Comparative Analysis. 2020 IEEE International IOT, Electronics and Mechatronics Conference, Vancouver, 9-12 September 2020, 1-6. https://doi.org/10.1109/IEMTRONICS51293.2020.9216414

[15] Trivedi, A., Gupta, A., Pachauri, R.K. and Chauhan, Y.K. (2017) Comparison of Perturb \& Observe and Ripple Correlation Control MPPT Algorithms for PV Array. 2016 IEEE 1 st International Conference on Power Electronics, Intelligent Control and Energy Systems, Delhi, 4-6 July 2016, 1-5. https://doi.org/10.1109/ICPEICES.2016.7853459

[16] Belkaid, A., Colak, U. and Kayisli, K. (2017) A Comprehensive Study of Different Photovoltaic Peak Power Tracking Methods. 2017 IEEE 6th International Conference on Renewable Energy Research and Applications, San Diego, 5-8 November 2017, 1073-1079. https://doi.org/10.1109/ICRERA.2017.8191221

[17] Ibnelouad, A., El Kari, A., Ayad, H. and Mjahed, M. (2017) A Comprehensive Comparison of the Classic and Intelligent Behavior MPPT Techniques for PV Systems. 2017 14th International Multi-Conference on Systems, Signals \& Devices, Marrakech, 28-31 March 2017, 526-531. https://doi.org/10.1109/SSD.2017.8166966

[18] Hamed, B.M and El-Moghany, M.S. (2012) Fuzzy Controller Design Using FPGA for Photovoltaic Maximum Power Point Tracking. International Journal of Advanced Research in Artificial Intelligence, 1, 14-21.

https://doi.org/10.14569/IJARAI.2012.010303

[19] Ali, A.I.M., Mohamed, E.E.M. and Youssef, A.R. (2018) MPPT Algorithm for GridConnected Photovoltaic Generation Systems via Model Predictive Controller. 2017 Nineteenth International Middle East Power Systems Conference, Cairo, 19-21 December 2017, 895-900. https://doi.org/10.1109/MEPCON.2017.8301286

[20] Samosir, A.S., Gusmedi, H., Purwiyanti, S. and Komalasari, E. (2018) Modeling and 
Simulation of Fuzzy Logic Based Maximum Power Point Tracking (MPPT) for PV Application. International Journal of Electrical and Computer Engineering, 8, 1315-1323. https://doi.org/10.11591/ijece.v8i3.pp1315-1323

[21] Youssef, A., El Telbany, M. and Zekry, A. (2018) Reconfigurable Generic FPGA Implementation of Fuzzy Logic Controller for MPPT of PV Systems. Renewable and Sustainable Energy Reviews, 82, 1313-1319.

https://doi.org/10.1016/j.rser.2017.09.093

[22] Bounechba, H., Bouzid, A., Nabti, K. and Benalla, H. (2014) Comparison of Perturb \& Observe and Fuzzy Logic in Maximum Power Point Tracker for PV Systems. Energy Procedia, 50, 677-684. https://doi.org/10.1016/j.egypro.2014.06.083

[23] Hussein Selman, N. (2016) Comparison Between Perturb \& Observe, Incremental Conductance and Fuzzy Logic MPPT Techniques at Different Weather Conditions. International Journal of Innovative Research in Science, Engineering and Technology, 5, 12556-12569. https://doi.org/10.15680/IJIRSET.2016.0507069

[24] Sasi, M.A. (2017) Fuzzy Logic Control of MPPT Controller for PV Systems. Master's Thesis, Memorial University of Newfoundland, St. John's.

[25] MathWorks Inc., Matlab R2020a. https://www.mathworks.com 